\title{
The Relationship between Positive Well-Being and Academic Assessment: Results from a Prospective Study on Dental Students
}

\author{
Cristina Teodora Preoteasa, Anca Axante, Anca Diana Cristea, and Elena Preoteasa
}

Faculty of Dental Medicine, "Carol Davila” University of Medicine and Pharmacy, 020021 Bucharest, Romania

Correspondence should be addressed to Cristina Teodora Preoteasa; cristina_5013@yahoo.com

Received 24 April 2016; Revised 3 September 2016; Accepted 6 September 2016

Academic Editor: Gwo-Jen Hwang

Copyright (c) 2016 Cristina Teodora Preoteasa et al. This is an open access article distributed under the Creative Commons Attribution License, which permits unrestricted use, distribution, and reproduction in any medium, provided the original work is properly cited.

\begin{abstract}
Background. Presumably, the academic stress that builds throughout the academic year has a negative effect on dental students' psychological well-being and may have a relationship with academic performance. This research aimed to analyse the variation of positive well-being in second-year dental students, across the academic semester, in relation to consecutive examinations as part of academic assessment system (1) and to observe the relationship between academic performance during semester evaluation period and dental students' positive well-being (2). Methods. A prospective study was conducted on second-year dental students, data on positive well-being being collected with WHO-Five Well-Being Index (WHO-5), at the beginning of the semester and after three consecutive mandatory examinations. Results. One hundred and forty-six dental students were included (77\% response rate). Repeated ANOVA showed a significant progressive decline of positive well-being over the semester, which was clinically significant for an important part of them. Students who performed better in the semester evaluation period registered higher well-being levels at the beginning of the semester but a more pronounced decline of it until the semester evaluation period. Conclusion. Based on this research, a relationship between positive well-being, academic assessments, and academic performance is suggested, when evaluating them in a prospective frame.
\end{abstract}

\section{Introduction}

Dentistry is considered a high-stress profession, beginning with the educational period in dental schools, viewed as a highly demanding and stressful learning environment $[1$, 2]. Anxiety, depression, and burnout associated with stress are psychological illnesses repeatedly mentioned in studies regarding not only dental professionals but also dental students [3-6]. Current data identify academic stress as a strong predictor of psychological well-being in medical and dental students, the heavy workload related to the demanding curricula, the frequent theoretical and practical examinations, the transition to clinical practice, and the necessity to acquire adequate clinical competencies and interpersonal skills, of great importance when dealing with a patient, being the most significant sources of stress from the student's perspective [7$10]$.
Education nowadays is more than a transmission of facts; it is also about helping the individual to reach his maximum potential, both personally and professionally [11]. Academic stress has a bidirectional effect on the learning experience: at an optimal level it is being considered to enhance learning, but, at an excessive level, it negatively affects academic performance and professional development [12]. Presumably, the academic stress builds throughout the academic year and in preclinical dental students is probably intensely linked to the frequent examinations, scheduled in waves at various moments across the semester, which are integrated into the assessment system used in some dental schools. Stress accumulation may have a negative effect on dental students' psychological well-being and may be related to the academic performance. Even if psychological well-being of medical and dental students is an issue relatively largely debated and researched, few studies focused on the positive dimension 
of well-being, and fewer studies focused on its relationship with academic performance, its importance being supported by the independent role played by the positive and negative mental states in quality-of-life and health outcomes [13], positive psychological well-being being presumably strongly linked to engagement and performance and to a healthy behaviour, being a strong predictor for long-term health outcomes, as shown in cohort studies [14].

The aim of this study was to analyse variations in the positive well-being of second-year dental students across the academic semester, in relation to consecutive examinations as part of academic assessment (1), and to observe the relationship between academic performance during semester evaluation period and dental students' positive well-being (2).

\section{Materials and Methods}

This study was approved by the Ethics Committee for Scientific Research at the "Carol Davila" University of Medicine and Pharmacy, Bucharest, Romania (PO-35-F-03, number 55).

2.1. Study Design and Settings. A prospective study was designed and implemented on a cohort of second-year dental students from the Faculty of Dental Medicine, "Carol Davila" University of Medicine and Pharmacy, Bucharest, Romania. Data was collected during the second semester of the 2014-2015 academic year, three consecutive times during the teaching period (in the beginning of the semester during a period of coursework without assessments and after two consecutive mandatory intermediate examinations) and one time during the semester evaluation period (after a mandatory final exam).

2.2. Participants. Students from two out of three series of second-year dental students who attended the above named university were invited to participate in this study. The educational process in this university comprises six years of study, each year being made up of three series of students, of about one hundred students. Enrolment was done considering all eligible subjects, who voluntarily agreed upon participation in this study. All participants were informed regarding the main characteristics of this study and a written informed consent was granted, at the beginning and also at the followup appointments.

2.3. Variables. Positive psychological well-being was evaluated by WHO-Five Well-Being Index (WHO-5). WHO-5 is an instrument developed at the Psychiatric Research Unit, Mental Health Centre North Zealand, Hillerod, Denmark, a World Health Organization Collaborating Centre, which measures self-reported positive psychological well-being. WHO-5 consists of a 5-item questionnaire, positively worded, with a time frame of evaluation consisting of the previous two weeks. Its interpretation is in accordance with the score obtained, which ranges from 0 to 100; the higher the score means the better the well-being. WHO-5 is also a depression screening tool. Obtaining a score below 50, or choosing answers with the minimum scores ("at no time" or "some of the time"), suggests poor well-being and recommendations are made to the participant to be tested for depression [1517]. In monitoring change, a difference in WHO-5 score of 10 points at consecutive evaluations is considered clinically significant [18-20]. The Romanian language version of WHO5 , available on the website of Psychiatric Research Unit at the Psychiatric Research Unit, Mental Health Centre North Zealand, Hillerod, Denmark, was used, which was previously tested, and it was demonstrated to have good psychometric properties as well-being scale and as a screening instrument for depression [20].

Student's academic performance during semester evaluation period was assessed by their grade-point average (GPA). For this study, grades were imported from the faculty database. Another two performance indicators were used, namely, the attendance to final exams (two categories were formed, namely, "present at all final exams" and "absent from at least one final exam") and the ability to pass all final exams (two categories were formed, namely, "passed all final exams" and "failed at least one final exam").

2.4. Data Collection, in regard to the Academic Calendar. Data on the level of positive well-being was collected by usage of a written questionnaire that included WHO-5, administered four times during the second semester of the 2014-2015 academic year, after coursework or examinations that were part of academic assessment.

In this Dental Faculty, the academic year is divided into two academic semesters (from October to February and from February to July). Each semester comprises a 14-week teaching period and a 4 -week semester evaluation period. The teaching period includes coursework, practical activities, and two intermediate examinations-one theoretical (scheduled after the first half of the teaching period) and one practical (scheduled at the end of the teaching period). These intermediate examinations are mandatory to pass (a grade of 5 out of 10 must be obtained), but they have little or no impact on the final grade. During semester evaluation period, students undergo mandatory final examinations, which can be regarded as major assessments, as they have the biggest impact on the final grade. A third examination period is organized in September, in which students that failed or were absent from mandatory final exams from the first or second academic semester can retake them.

Therefore, for one subject trained for one semester, the assessment system usually includes three examinations, all mandatory to pass, that is, two intermediate consecutive examinations taken during the teaching period (one theoretical and one practical) and one final exam taken during evaluation period. Also, GPA is the criterion for ranking students, the first one hundred and thirty of them being included in the tuition-free group.

In this study, timing for data collection (Figure 1) was related to different levels of demand of the academic activities in terms of assessments, as follows:

(i) T1: 2nd week of teaching period, corresponding to the beginning of the second academic semester, when focus is mainly on teaching the basic theoretical 


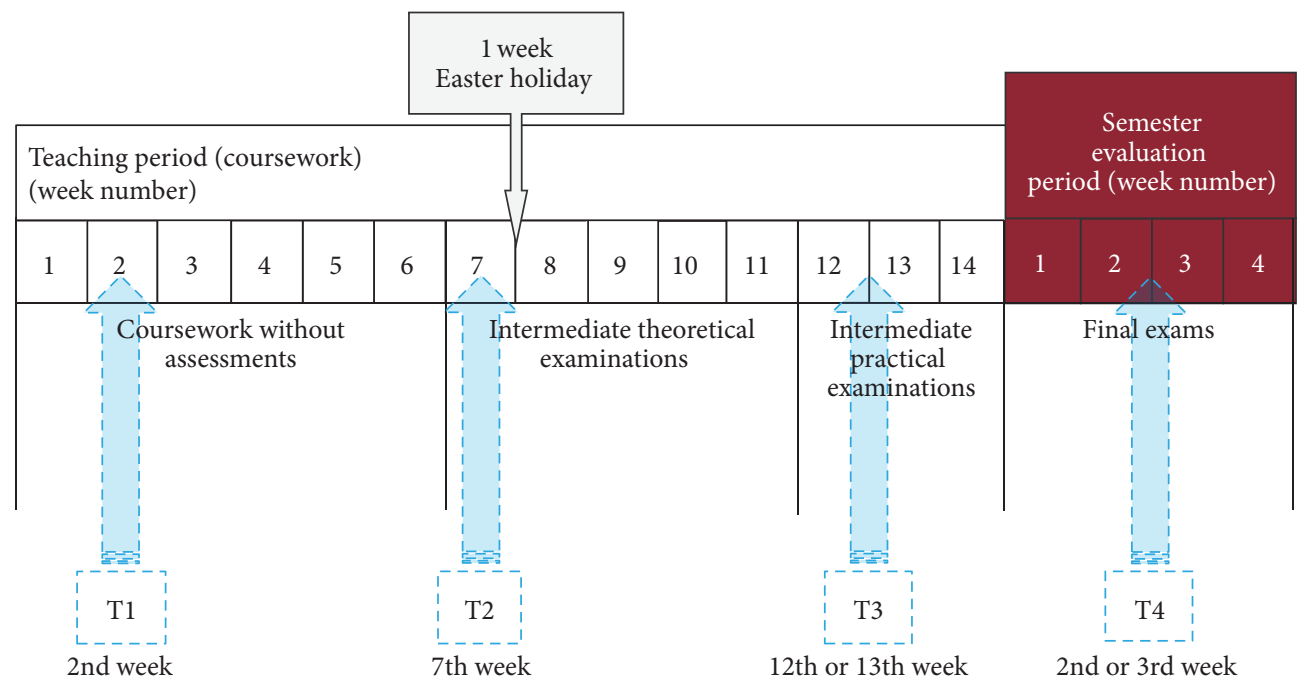

FIGURE 1: Timing for data collection, in regard to the assessments calendar of 2014-2015 second academic semester.

knowledge and practical skills, examinations of any kind being scarce.

(ii) T2: 7th week of the teaching period, corresponding to the middle of the semester, during which intermediate theoretical examinations are scheduled for many of the courses taken; the questionnaire was addressed immediately after a mandatory written examination, the first scheduled in the second semester.

(iii) T3: 12th or 13th week of the teaching period, corresponding to the end of the teaching period, during which students have practical examinations for most of the courses taken; the questionnaire was administered immediately after a mandatory practical examination.

(iv) T4: 2nd or 3rd week of the semester evaluation period; the questionnaire was given just after taking a mandatory written final exam.

2.5. Data Analysis. Missing data, corresponding to not fully answering the questionnaire all four times, was managed by exclusion of the subject from the analysis.

Repeated ANOVA measures were used to evaluate changes of positive psychological well-being over time. Because data violated the assumption of sphericity, a Greenhouse-Geisser correction was used. Post hoc Bonferroni statistical analysis was performed.

SPSS Statistics for Windows was used for data analysis. Significance was set at $p<0.05$ (significance level 95\%) for all statistical tests and marked by the "*" symbol.

\section{Results}

3.1. Participants. One hundred and eighty-nine second-year dental students were registered in the two examined series. Out of these, one hundred and forty-six dental students completely filled the questionnaire all four times and were included in this study, the corresponding response rate being
TABLE 1: Effect of time on students' positive psychological wellbeing, across the second academic semester.

(a)

\begin{tabular}{lccc}
\hline \multicolumn{3}{c}{ WHO-5 score } \\
Time & Mean & SD & \\
\hline T1 & 66.43 & 13.45 & Greenhouse-Geisser adjusted \\
T2 & 65.26 & 16.58 & $F(2.49 ; 360.65)=18.15, p<0.001^{*}$, \\
T3 & 60.79 & 15.87 & partial $\eta^{2}=0.111$ \\
T4 & 55.94 & 22.40 & \\
\hline
\end{tabular}

(b)

\begin{tabular}{lcccc}
\hline \multicolumn{3}{c}{ Bonferroni statistical analysis } & & \\
Comparison & Mean difference & Standard error & \multicolumn{2}{c}{$95 \%$ CI } \\
& & & Lower & Upper \\
\hline T1 versus T2 & 1.17 & 1.35 & -2.44 & 4.80 \\
T2 versus T3 & $4.46^{*}$ & 1.30 & 0.98 & 7.94 \\
T3 versus T4 & $4.84^{*}$ & 1.53 & 0.74 & 8.95 \\
T1 versus T4 & $10.49^{*}$ & 1.97 & 5.21 & 15.77 \\
\hline
\end{tabular}

$77 \%$. Most of them were females ( $n=117 ; 80 \%)$, being twenty or twenty-one years old ( $n=141 ; 97 \%)$, and of Romanian nationality $(n=139 ; 95 \%)$.

3.2. Change of Students' Positive Well-Being, in relation to Consecutive Examinations as Part of Academic Assessment System. The results show that there was a significant effect of time on students' positive well-being, and it is being suggested that examinations of different types (theoretical or practical, written or oral, and intermediate or final evaluations), or maybe simply the stress related to the academic assessments, contribute to the decrease of the student's positive psychological well-being throughout the academic semester. Analysing the WHO-5 scores across the semester, a decline of positive psychological well-being was noticed, which, by its mean score, was clinically significant (Table 1). 


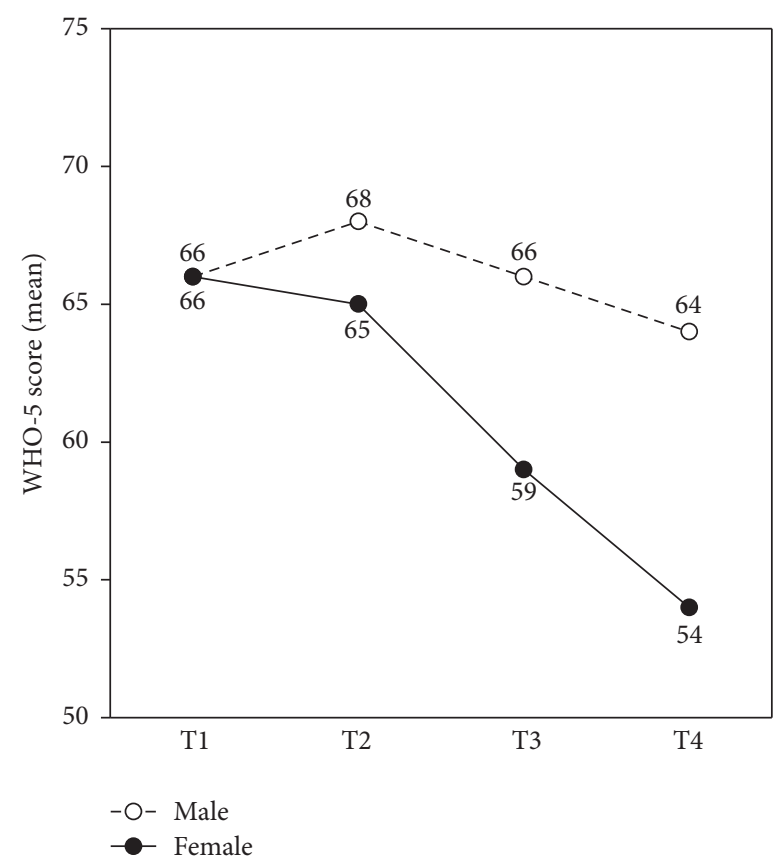

Figure 2: Gender breakdown of the change of dental students' positive well-being across the second academic semester.

Gender breakdown revealed that male and female dental students were rather different in terms of variation of positive well-being across the second semester. In the beginning of the semester (T1), they registered similar positive wellbeing levels, but during the semester while male students registered rather stable positive well-being levels, female students showed a clinically significant worsening of the positive well-being (Figure 2). Therefore, according to these results, female students are more prone to the lowering of the well-being level during assessment periods than male students.

Thirty-one (21\%) dental students in T1, thirty-three (23\%) dental students in T2, thirty-nine (27\%) dental students in $\mathrm{T} 3$, and fifty-nine (40\%) dental students in T4 were recommended to be tested for depression, according to WHO-5 interpretation. Students that were not recommended to be tested for depression in the semester evaluation period registered rather similar positive psychological well-being levels across the semester, suggesting a more stable emotional state. Students that were recommended to be tested for depression in the semester evaluation period showed a general tendency of a progressive decline of positive psychological well-being during the semester (Figure 3). Therefore, it is being suggested that experiencing low levels of positive psychological well-being in the semester evaluation period may appear as a result of the cumulative effect of stressors during the academic semester, this being observed for an important part of the students.

3.3. Relation between Academic Performance during Semester Evaluation Period and Dental Students' Positive Psychological Well-Being. Students with better academic performance, ranked according to their GPA, registered higher levels of

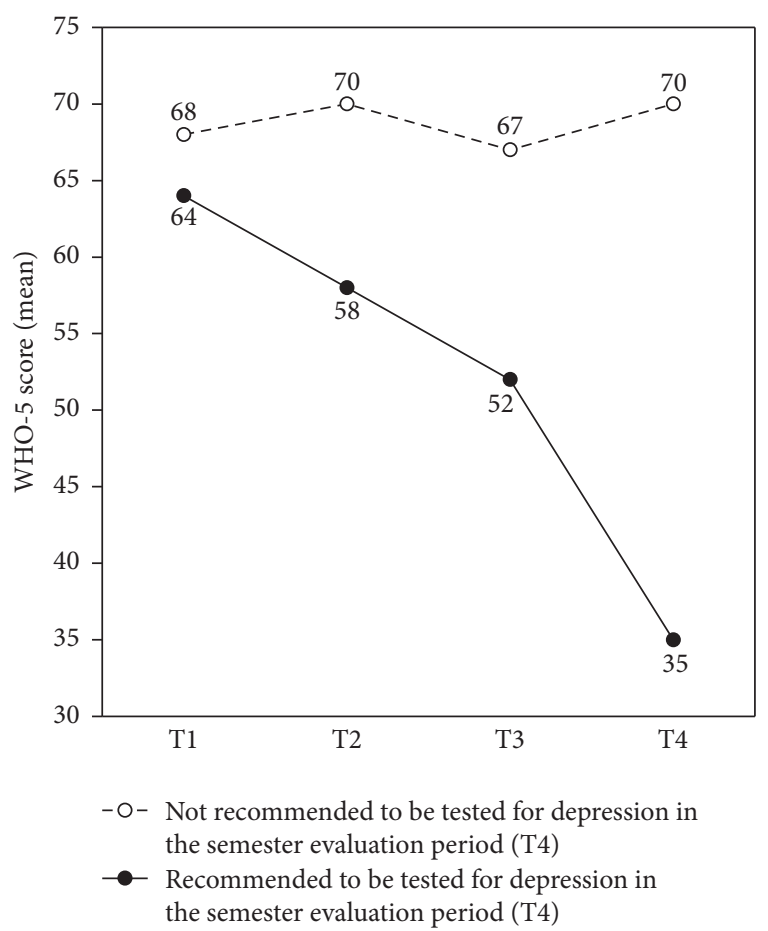

FIGURE 3: Subgroup analysis of the change of dental students' positive well-being, according to their recommendation to be tested for depression in the semester evaluation period (T4).

positive psychological well-being during the first half of the semester, in T1 and T2, during the periods when focus was mainly on acquirement of theoretical knowledge and practical skills, and examinations were less frequent. Even so, during the periods with more frequent examination (T3 and T4), both categories of students registered similar levels of positive well-being (Figure 4).

Twenty-five dental students failed to attend at least one final exam. Students with better academic performance, in terms of attendance to all final exams, registered also higher levels of positive psychological well-being at the beginning of the semester (T1) and a progressive decrease of positive psychological well-being across the semester, which by its mean score can be considered clinically significant. The students that failed to attend at least one final exam showed lower levels of well-being at the beginning of the semester (T1) and lower variations of the positive well-being score across the academic semester. Also, during the periods with more frequent examination (T3 and $\mathrm{T} 4$ ), both categories of students registered similar levels of positive well-being (Figure 5).

Twenty-six dental students failed one or more of their final exams. Students with better academic performance, in terms of ability to pass all final exams, registered higher levels of positive psychological well-being at the beginning of the semester (T1) but showed a progressive decline of well-being across the academic semester, with large variation of WHO- 5 scores, which by its mean value was clinically significant. Students that had failed one or more of their final exams registered lower levels of well-being at the beginning 


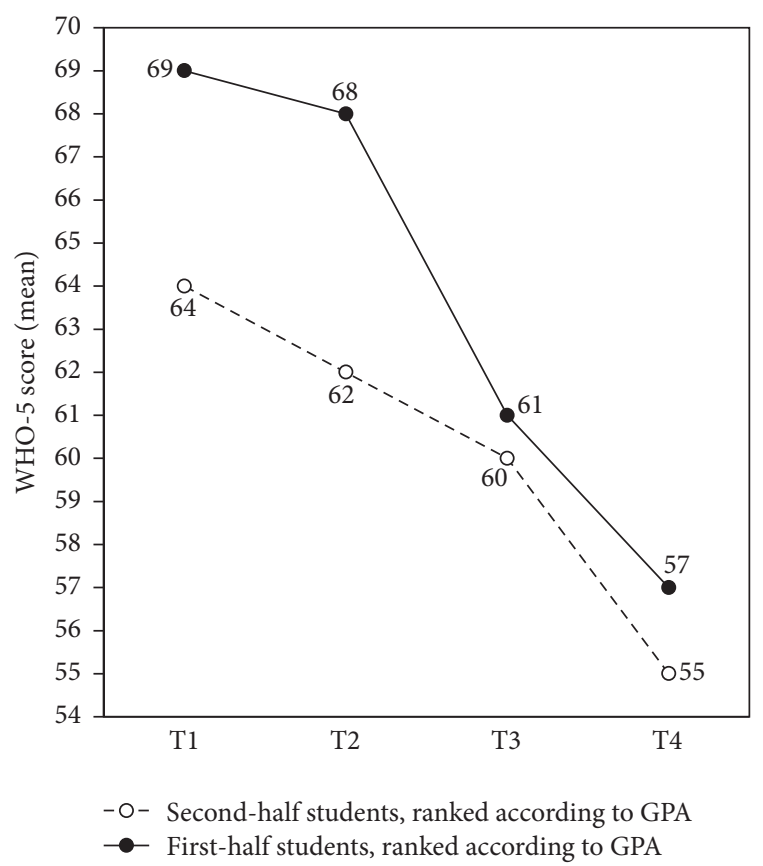

FIgURE 4: Subgroup analysis of the change of dental students' positive well-being, according to their GPA related ranking.

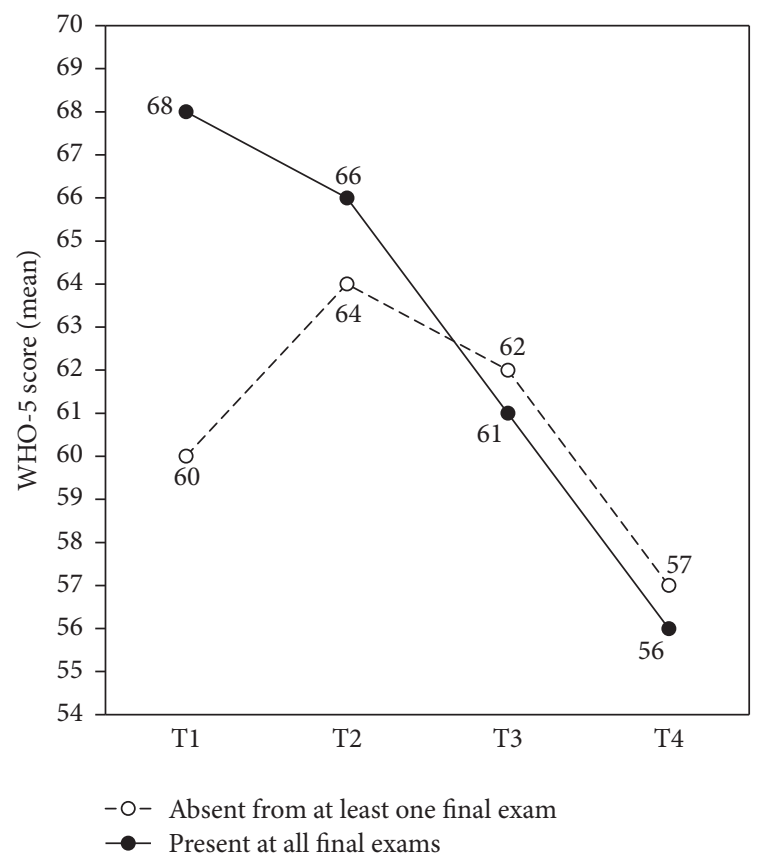

FIGURE 5: Subgroup analysis of the change of dental students' positive well-being, according to their attendance of final exams.

of the semester (T1) and a more stable well-being level across the semester, with lower variations of the WHO-5 score (Figure 6).

\section{Discussion}

Dental students showed during the academic semester a significant progressive decline of their positive well-being,

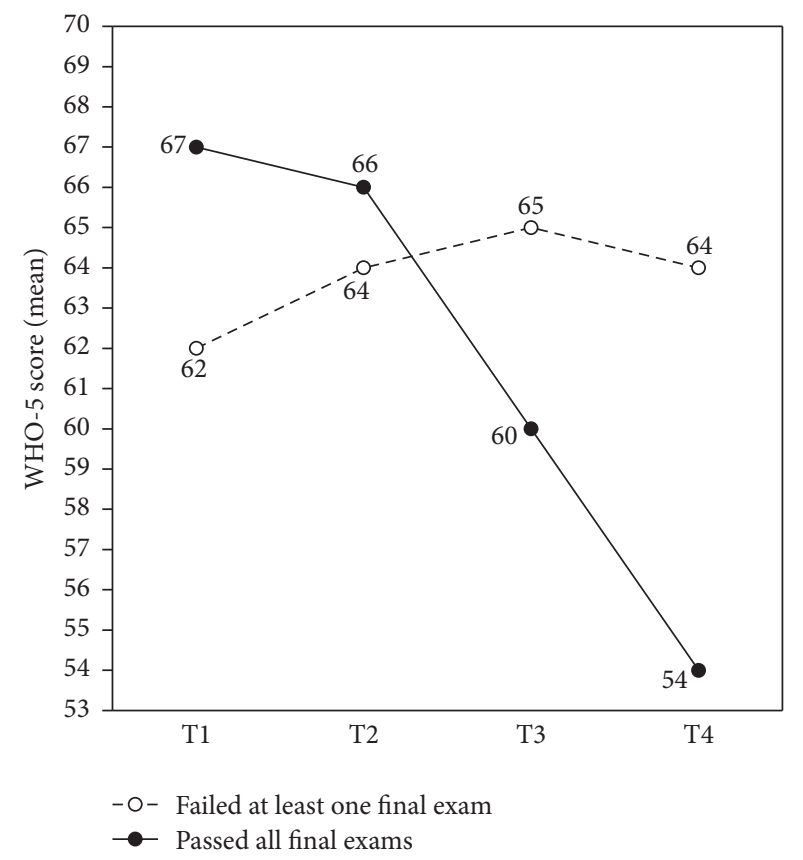

FIGURE 6: Subgroup analysis of the change of dental students' positive well-being, according to their ability to pass all final exams.

which was concordant with the increase of the academic demand in terms of consecutive examinations, as part of the assessment system. Students with better academic performance in the semester evaluation period (in terms of higher GPAs, attendance of all final examinations, and ability to pass all exams) tended to register higher positive well-being levels at the beginning of the semester, when focus is mainly on acquirement of theoretical knowledge and practical skills and examinations are less frequent, but were more prone to a higher decrease of the well-being level across the semester.

In this study, the level of positive well-being of dental students was found to be rather similar to population norms (i.e., of about 70 , according to Bech $[16,17])$ only in the first half of the semester and decreased compared to it in the second half of the semester, its lowest level being observed, as expected, in the semester evaluation period. The relatively dramatic decline of dental students' positive well-being was probably related to the exposure to academic stressors, starting with the consecutive examinations and the need to cope with a lot of information, and is associated with the effect of stressors, such as fatigue. In this context, considering the moments used for data collection (i.e., immediately after three different types of mandatory examinations) and also considering examinations are known to be highly stressful for students, which act as an acute stressor, the lowering of the positive well-being level may be seen as a predictable event [21, 22]. Our results suggest that stressors related to examinations have a cumulative effect and may lead to a worrying situation; in this study about $40 \%$ of the students were recommended to be tested for depression in the semester evaluation period. Considering that this routine of academic assessments is nearly the same twice a year, during all six years of dental training in this particular faculty, questions of how well dental 
students adapt, or what are the side effects, arise. In this regard, many previous researches drew attention towards the decreased level of well-being of medical and dental students, highlighting that unfavourable stress and depression are significantly higher during medical training than before its onset, and students' stress increases in time, being suspected to have detrimental effects on performance and health [2326]. Therefore, recommendations were made to attempt to lower the negative effect of academic stressors on dental students [27], as there is a perceived need to improve the learning environment [28], with presumably positive effect on the increase of their performance and their long-term ability to acquire theoretical knowledge and practical skills, for transforming them into competitive practitioners.

Gender differences also arise from the results of our study: at baseline both male and female students show rather similar positive well-being levels, but female students show a greater decrease of the well-being level during the semester, whereas male students seem to have a more stable well-being level. Previous studies reported various results, part of them being similar to the ones of this study, females experiencing a higher decrease of well-being level being explained by the higher levels of stress experienced by women, who are more prone to anxiety than men, and assessments being found invoking more stress in female than in male students [29]. Some studies, as the one of Lei et al., found rather similar prevalence of depression among male and female medical students in China [30]; meanwhile others, as the one of Yusoff et al., found that male students suffer more from depression symptoms compared to female students from Malaysia [24]. Probably cultural differences are responsible for this evidence disagreement.

The relationship between well-being and academic performance was mainly addressed by cross-sectional studies, which reported a weak positive relationship between them [4, 31-33]. Very few longitudinal studies have been published on samples formed by medical and dental students in this regard, and even fewer were the ones considering the positive dimension of well-being-this approach seeming relevant when considering that positive psychological states are seen as more important in explaining performance than the negative ones [34]. According to this study's results, positive well-being is a highly dynamic state; thus, for understanding its relation to academic performance, prospective researches may give more accurate information than cross-sectional ones. According to our results, students with better academic performance in the semester evaluation period (in terms of higher GPA, ability to pass all exams, and attendance to all final examinations) tend to register higher positive well-being levels at the beginning of the semester, a moment which is relatively remote in time. This might be explainable by the higher engagement in the learning activities by the students with higher well-being levels, the outcome being better performance in the following examination process. These results are in accordance with the few previous prospective researches identified. Rather similarly, Yusoff et al. [35], in a study on Malaysian medical students, found a relationship between GPAs and stress levels in less stressful periods, but not in more stressful periods (i.e., final examinations).
Silverstein and Kritz-Silverstein [25] observed that US dental students that had higher stress scores at the beginning of the first year reported lower GPAs for the respective year, meaning worse performance. The burnout syndrome, another element that can lead to the decrease of the personal accomplishment level, was also found to be in constant acceleration from the first to the final year of study [27]. In this study, students that failed their final exams in the summer evaluation period registered a lower well-being level at the beginning of the semester but rather unexpectedly showed also a low variation of it across the semester, consequently at the end of the semester their well-being level being higher than that of the students who passed all final exams. Previous researches suggest that students who fail their final examinations have higher psychological distress compared to those who pass [36]. Possibly the low variation of the wellbeing level found in this research is related to a decreased engagement in academic activities-therefore the effect of the stressors being limited upon them-and to the fact that the fallen exams sustained during the summer examination period can be retaken in the fall-examination period.

Limitations of this study include the drawing of the sample from only one dental school, and also the structure of the sample, for example, is made up mainly of female students, gender possibly being a confounding factor: unfortunately medical universities in Romania have a predominantly female studying population. Even so, considering data regarding positive well-being and its relation to academic assessment is scarce, even more limited for dental students from EastCentral Europe, this study gives information that helps augmenting the knowledge and consequently shedding more light on this issue. Also, the follow-up period in this study is rather limited (i.e., one academic semester). Even if without a doubt interest should be focused on what happens in the long term, in order to clarify that it is helpful to understand what happens on a shorter time scale, such as an academic semester or an academic year, these intervals are appropriate when considering the general structure of the academic training period (academic years divided into academic semesters). This research also suggests there is a relationship between positive psychological well-being and academic performance in dental students, even so, this research only addressed the issue of academic stress related to examinations, and therefore we need to understand the role that other academic stressors play, in order to identify ways of improving the educational process in dental schools.

\section{Conclusions}

The results of this research, considering also its limitations, indicate that an important part of the dental students register a clinically significant decrease of their positive well-being across the academic semester, which seems related to the progressive increase of academic demand in this time span, as consecutive examinations which are part of the assessment system. A relationship between positive well-being and academic performance was observed, when evaluating them in a prospective frame: students with better academic performance in the semester evaluation period tend to 
register higher positive well-being levels at the beginning of the semester and a higher decrease of well-being across the semester.

In this context, making students aware of the risks involved by the lowering of the positive well-being level and interventions meant to enhance student's well-being, implemented in university settings, seem beneficial. Early intervention seems appropriate when considering dentists have high level of stress exposure during dental training and dental career and also the negative effects at both personal and professional level that may occur.

\section{Competing Interests}

The authors declare that there is no conflict of interests regarding the publication of this paper.

\section{Acknowledgments}

This research was supported by a postdoctoral fellowship from the project "Programme of Excellence in Multidisciplinary Doctoral and Postdoctoral Research of Chronic Diseases," Contract no. POSDRU/159/1.5/S/133377, project cofinanced from European Social Fund through Sectoral Operational Programme for Human Resources Development (SOP HRD) 2007-2013.

\section{References}

[1] A. Polychronopoulou and K. Divaris, "Perceived sources of stress among Greek dental students," Journal of Dental Education, vol. 73, no. 5, pp. 631-639, 2005.

[2] R. E. Rada and C. Johnson-Leong, "Stress, burnout, anxiety and depression among dentists," Journal of the American Dental Association, vol. 135, no. 6, pp. 788-794, 2004.

[3] M. A. Henning, S. J. Hawken, and A. G. Hill, "The quality of life of New Zealand doctors and medical students: what can be done to avoid burnout?" New Zealand Medical Journal, vol. 122, no. 1307, pp. 102-110, 2009.

[4] C. Atalayin, M. Balkis, H. Tezel, B. Onal, and G. Kayrak, "The prevalence and consequences of burnout on a group of preclinical dental students," European Journal of Dentistry, vol. 9, no. 3, pp. 356-363, 2015.

[5] L. N. Dyrbye, M. R. Thomas, A. Eacker et al., "Race, ethnicity, and medical student well-being in the United States," Archives of Internal Medicine, vol. 167, no. 19, pp. 2103-2109, 2007.

[6] H. Jurkat, S. Höfer, L. Richter, M. Cramer, and A. Vetter, "Quality of life, stress management and health promotion in medical and dental students. A comparative study," Deutsche Medizinische Wochenschrift, vol. 136, no. 23, pp. 1245-1250, 2011.

[7] M. E. Rogers, P. A. Creed, and J. Searle, "Person and environmental factors associated with well-being in medical students," Personality and Individual Differences, vol. 52, no. 4, pp. 472477, 2012.

[8] S. A. Al-Saleh, E. M. Al-Madi, N. S. Al-Angari, H. A. AlShehri, and M. M. Shukri, "Survey of perceived stress-inducing problems among dental students, Saudi Arabia," Saudi Dental Journal, vol. 22, no. 2, pp. 83-88, 2010.
[9] L. N. Dyrbye, M. R. Thomas, and T. D. Shanafelt, "Systematic review of depression, anxiety, and other indicators of psychological distress among U.S. and Canadian medical students," Academic Medicine, vol. 81, no. 4, pp. 354-373, 2006.

[10] C. Nandini, D. Suvajit, M. Kaushik, and C. Chandan, 'Students' and teachers' perceptions of factors leading to poor clinical skill development in medical education: a descriptive study," Education Research International, vol. 2015, Article ID 124602, 3 pages, 2015.

[11] M. J. Sleigh and D. R. Ritzer, "Beyond the classroom: developing students' professional social skills," Association for Psychological Science Monitor, vol. 17, no. 9, pp. 51-53, 2004.

[12] M. S. B. Yusoff, A. F. Abdul Rahim, and M. J. Yaacob, "Prevalence and sources of stress among Universiti Sains Malaysia medical students," Malaysian Journal of Medical Sciences, vol. 17, no. 1, pp. 30-37, 2010.

[13] F. A. Huppert and J. E. Whittington, "Evidence for the independence of positive and negative well-being: implications for quality of life assessment," British Journal of Health Psychology, vol. 8, no. 1, pp. 107-122, 2003.

[14] M. Shi, X. Wang, Y. Bian, and L. Wang, “The mediating role of resilience in the relationship between stress and life satisfaction among Chinese medical students: a cross-sectional study," $B M C$ Medical Education, vol. 15, no. 1, article 16, 2015.

[15] B. Löwe, R. L. Spitzer, K. Gräfe et al., "Comparative validity of three screening questionnaires for DSM-IV depressive disorders and physicians' diagnoses," Journal of Affective Disorders, vol. 78, no. 2, pp. 131-140, 2004.

[16] P. Bech, "Subjective positive well-being," World Psychiatry, vol. 11, no. 2, pp. 105-106, 2012.

[17] P. Bech, Clinical Psychometrics, Wiley-Blackwell, Oxford, UK, 2012.

[18] R. Singh, M. Goyal, S. Tiwari, A. Ghildiyal, S. M. Nattu, and S. Das, "Effect of examination stress on mood, performance and cortisol levels in medical students," Indian Journal of Physiology and Pharmacology, vol. 56, no. 1, pp. 48-55, 2012.

[19] C. W. Topp, S. D. Østergaard, S. Søndergaard, and P. Bech, "The WHO-5 well-being index: a systematic review of the literature," Psychotherapy and Psychosomatics, vol. 84, no. 3, pp. 167-176, 2015.

[20] C. T. Preoteasa and E. Preoteasa, "Psychometric properties of romanian version of who- 5 well-being index in dental students," Romanian Journal of Oral Rehabilitation, vol. 7, no. 3, pp. 21-27, 2015.

[21] R. S. Naidu, J. S. Adams, D. Simeon, and S. Persad, "Sources of stress and psychological disturbance among dental students in the West Indies," Journal of Dental Education, vol. 66, no. 9, pp. 1021-1030, 2002.

[22] A. M. Alzahem, H. T. van der Molen, A. H. Alaujan, H. G. Schmidt, and M. H. Zamakhshary, "Stress amongst dental students: a systematic review," European Journal of Dental Education, vol. 15, no. 1, pp. 8-18, 2011.

[23] C. T. Preoteasa, M. V. Constantinescu, and E. Preoteasa, "Predicting psychological well-being of dental students during semester evaluation period: a prospective study," Stomatology Edu Journal, vol. 3, no. 1, pp. 47-53, 2016.

[24] M. S. B. Yusoff, A. F. Abdul Rahim, A. A. Baba, S. B. Ismail, M. N. Mat Pa, and A. R. Esa, "The impact of medical education on psychological health of students: a cohort study," Psychology, Health and Medicine, vol. 18, no. 4, pp. 420-430, 2013. 
[25] S. T. Silverstein and D. Kritz-Silverstein, "A longitudinal study of stress in first-year dental students," Journal of Dental Education, vol. 74, no. 8, pp. 836-848, 2010.

[26] Y. Birks, J. McKendree, and I. Watt, "Emotional intelligence and perceived stress in healthcare students: a multi-institutional, multi-professional survey," BMC Medical Education, vol. 9, no. 1, article 61, 2009.

[27] R. Gorter, R. Freeman, S. Hammen, H. Murtomaa, A. Blinkhorn, and G. Humphris, "Psychological stress and health in undergraduate dental students: fifth year outcomes compared with first year baseline results from five European dental schools," European Journal of Dental Education, vol. 12, no. 2, pp. 61-68, 2008.

[28] E. M. AlHamdan, H. I. Tulbah, G. A. AlDuhayan, and L. S. AlBedaiwi, "Preferences of dental students towards teaching strategies in two major dental colleges in Riyadh, Saudi Arabia," Education Research International, vol. 2016, Article ID 4178471, 8 pages, 2016.

[29] M. P. Lyndon, J. M. Strom, H. M. Alyami et al., "The relationship between academic assessment and psychological distress among medical students: a systematic review," Perspectives on Medical Education, vol. 3, no. 6, pp. 405-418, 2014.

[30] X. Y. Lei, L. M. Xiao, Y. N. Liu, Y. M. Li, and J. Pietschnig, "Prevalence of depression among chinese university students: a meta-analysis," PLoS ONE, vol. 11, no. 4, Article ID e0153454, 2016.

[31] H. Ayyash-Abdo and M.-J. Sánchez-Ruiz, "Subjective wellbeing and its relationship with academic achievement and multilinguality among Lebanese university students," International Journal of Psychology, vol. 47, no. 3, pp. 192-202, 2012.

[32] J. Por, L. Barriball, J. Fitzpatrick, and J. Roberts, "Emotional intelligence: its relationship to stress, coping, well-being and professional performance in nursing students," Nurse Education Today, vol. 31, no. 8, pp. 855-860, 2011.

[33] S. M. Trucchia, M. S. Lucchese, J. E. Enders, and A. R. Fernández, "Relationship between academic performance, psychological well-being, and coping strategies in medical students," Revista de la Facultad de Ciencias Médicas, vol. 70, no. 3, pp. 144-152, 2013.

[34] M. Salanova, S. Agut, and J. M. Peiró, "Linking organizational resources and work engagement to employee performance and customer loyalty: the mediation of service climate," Journal of Applied Psychology, vol. 90, no. 6, pp. 1217-1227, 2005.

[35] M. S. Yusoff, A. R. Esa, M. N. Mat Pa, S. C. Mey, R. A. Aziz, and A. F. Abdul Rahim, "A longitudinal study of relationships between previous academic achievement, emotional intelligence and personality traits with psychological health of medical students during stressful periods," Education for Health, vol. 26, no. 1, pp. 39-47, 2013.

[36] M. S. B. Yusoff, "Associations of pass-fail outcomes with psychological health of first-year medical students in a Malaysian medical school," Sultan Qaboos University Medical Journal, vol. 13, no. 1, pp. 107-114, 2013. 


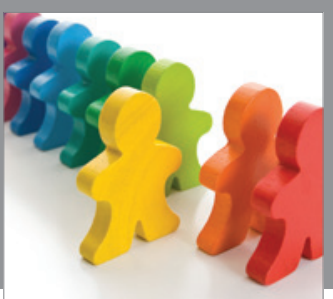

Autism

Research and Treatment
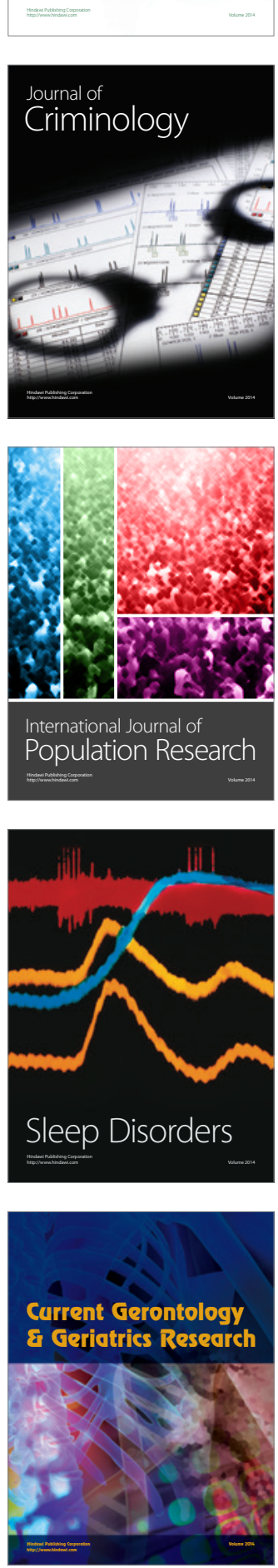

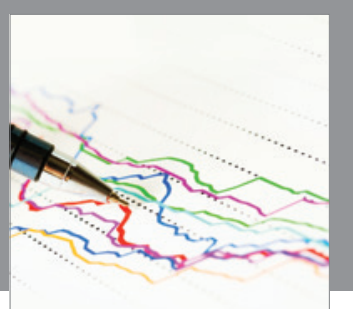

Economics

Research International
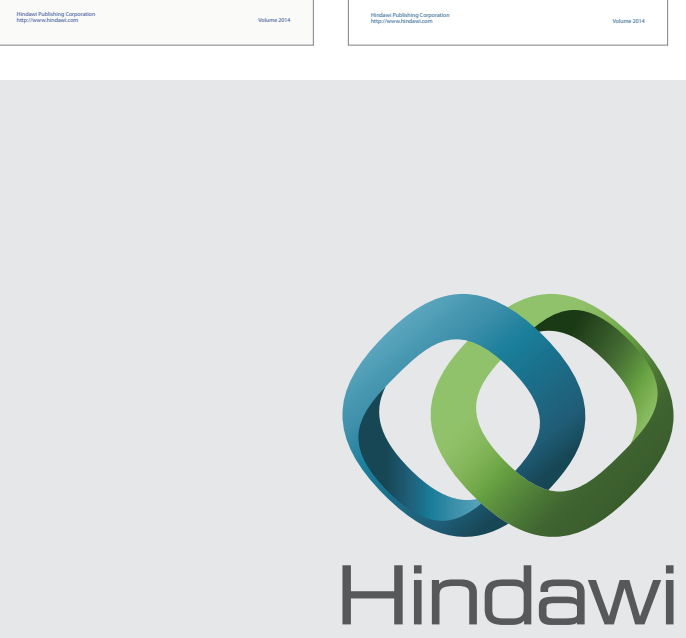

Submit your manuscripts at

http://www.hindawi.com
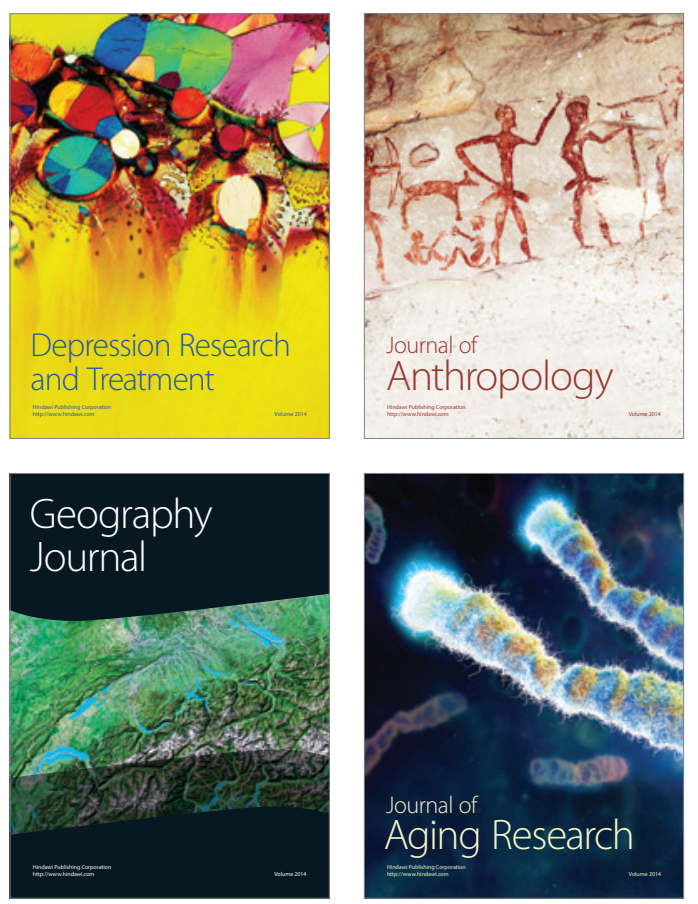
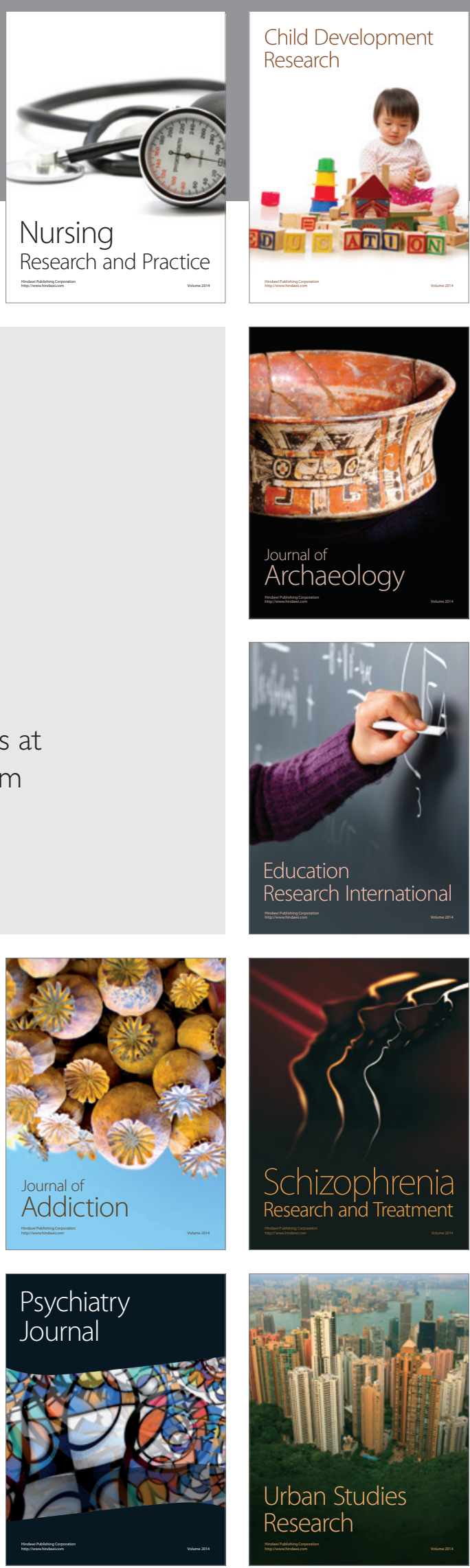